\title{
PENERAPAN HIDUP SEHAT MELALUI PENYULUHAN OLAHRAGA DALAM KEHIDUPAN SEHARI HARI
}

\author{
Susy Olivia Lontoh ${ }^{1}$, Yemima Graciela \\ ${ }^{1}$ Bagian Ilmu Faal Fakultas Kedokteran Universitas Tarumanagara \\ Surel : susyo@fk.untar.ac.id \\ ${ }^{2}$ Mahasiswa Fakultas Kedokteran Universitas Tarumanagara \\ Surel: Yemimagraciella@gmail.com
}

\begin{abstract}
During the pandemic COVID-19, all of our daily activities are very limited in moves, the pattern of life sedentary. The Program of health education is a form of effort to improve and maintain the habit of physical exercise in the house as well as exercising secarta regular and correct way increase the knowledge and insight they related the importance of exercise and good physical activity and affect their attitude so in the habit of day-to-day diligently sports that have an impact on improving health status. Extension activities health education sports was held on 27 May 2021 Friday online, starting at 13: 00 PM, attended by 15 participants, the material presented is related to physical activity, the benefits, the tips a good sport during the pandemic, the form of physical activity that can be done at home as well as prokes health during the pandemic based on the GERMAS. 11 participants of physical activity is less and 4 participants physical activity enough. 9 participants do sports 0 -1 times per week. The results obtained show low exercise as well as high levels of physical activity is low. The results of the posttest showed after the extension of an increase of knowledge related to physical activity and sport by $31.3 \%$. Counseling sports impact to participants because of the insight and knowledge of physical activity and sports is increased.
\end{abstract}

Keywords: sedentary lifestyle, counseling, sports

\section{ABSTRAK}

Selama pandemi COVID-19, semua kegiatan sehari-hari kita sangat terbatas dalam bergerak, polahidup sedentary. Program health education merupakan bentuk usaha meningkatkan serta mempertahankan kebiasaan latihan fisik di rumah serta berolahraga secarta teratur dan benar dengan cara meningkatkan pengetahuan serta wawasan mereka terkait pentingnya olahraga serta aktivitas fisik yang baik dan mempengaruhi sikap mereka agar di kebiasaan sehari-hari rajin olahraga yang berdampak pada peningkatkan derajat kesehatan. Kegiatan penyuluhan edukasi kesehatan olahraga dilaksanakan tanggal 27 Mei 2021 hari Jumat secara daring, dimulai pukul 13.00 WIB, dihadiri 15 peserta, materi yang disampaikan terkait aktivitas fisik, manfaatnya, tips olahraga yang baik saat pandemi, bentuk aktivitas fisik yang dapatdilakukan dirumah serta prokes kesehatan selama pandemi berdasarkan GERMAS. 11 peserta aktivitas fisik kurang dan 4 peserta aktivitas fisik cukup. 9 peserta melakukan olahraga 0-1 kali perminggu. Hasil yang didapat memperlihatkan rendahnya berolahraga serta tingginya tingkat aktivitas fisik rendah. Hasil posttest memperlihatkan setelah penyuluhan terjadi peningkatan pengetahuan terkait aktivitas fisik dan olahraga sebesar $31.3 \%$. Penyuluhan olahraga berdampak ke peserta karena wawasan dan pengetahuan aktivitas fisik serta olahraga meningkat.

Kata kunci: sedentary lifestyle, penyuluhan, olahraga

\section{PENDAHULUAN}

Aktivitas fisik adalah semua bentuk yang mencakup rekreasi aktif, partisipasi olahraga, bersepeda jalan kaki sekitar rumah, kegiatan di tempat kerja seperti naik turun tangga dikantor dan di sekitar rumah seperti menyapu, mengepel serta membersihkan halaman. Bentuk aktivitas fisik tidak harus berolahraga, kegiatan seperti berolahraga bermain, menari, berkebun, dan bahkan membersihkan rumah dan membawa belanjaanberat adalah bagian dari aktif secara fisik. (WHO,2020). Aktivitas fisik penting bagi orang-orang dari segala usia agar mempunyai kemampuan untuk seaktifmungkin, dapat di mulai istirahat sejenak dari duduk, bergerak disertai peregangan selama 3-5 menit dapat membuat tonus otot tidak tegang, aliran darah berjalan dengan baik serta massa otot dipertahankan serta memperbaiki mental karena mengurangi beban pikiran karena olahraga yang dijadikan rutinitas adalah hal yang menyenangkan serta hubungan 
dengan keluargadan teman tetap harmonis. (WHO,2020)

Aktivitas fisik yang dilaksanakan secara tepat dan benar membantu berat badan tidak bertambah, pengaturan tekanan darah dan kadar gula darah dapat dikontrol. Ketahanan massa otot, kelenturan tubuh, densitas tulang yang baik sehingga keseimbangan dan kebugaran tubuh seseorang dapat tercapai maksimal dapat dicapai dengan olahraga secara benar, teratur dan terukur. Orang tua diharapkan juga berolahraga untuk menjaga stabilitas tubuh dan alat gerak sehingga resiko cedera dan jatuh minimal. Aktivitas fisik dan olahraga yang tepat dan teratur membuat seorang anak ketrampilan motorik meningkat, mempererat dalam hubungan pertemanan dengan teman sebaya, meningkatkan hormon pertumbuhan sehingga tumbuh dan kembang anak berjalan lancar. Mencegah depresi, fungsi kognitif tetap dan kondisi demensia dapat dihindari dapat terjadi dalam kesehatan mental saat teratur berolahraga. (WHO,2020), (Pascoe M,2020)

Seseorang dalam melakukan aktifitas fisik dapat dilakukan kapan saja dan memungkinkan melakukan aktivitas fisik intensitas sedang dan tinggi. Anjuran dalam beraktivitas fisik yang tepat dan benar adalah lama kegiatan 30 menit dilakukan seminggu 3 sampai 5 kali dengan bentuk aktivitas fisik yang dapat dikerjakan seperti dansa, gerakan jongkok berdiri saat membersihkan rumah atau sambil berekreasi juga berolahraga sepeda. (WHO ,2020)

Selama pandemi COVID-19, semua kegiatan sehari-hari kita sangat terbatas dalam bergerak. Isolasi dan karantina berkepanjangan akibat pandemi COVID-19 menyebabkan pola hidup sedentary sehingga terjadi penggurangan dalam pengeluaran energi dapat menyebabkan , kelebihan berat badan (obesitas), peningkatan morbiditas danprevalensi penyakit tidak menular(penyakit jantung, diabetes, hipertensi). Untuk mencegah kondisi tersebut maka dianjurkan olahraga serta aktivitas fisikyang teratur. (Booth,2017),( Pedersen,2015)

\section{Permasalahan Mitra}

Masa karantina mandiri berkepanjangan akibat Covid-19 mempengaruhi gaya hidup seperti malas bergerak, malas melakukan aktivitas fisik seperti berjalan, berolahraga serta Sebagian besar waktu kegiatan fisik dikerjakan didalam ruangan. Permasalahan yang diuraikan menyebabkan peningkatan berat badan yang memicu obesitas, resiko penyakit jantung, kencing manis serta komorbid dari Covid-19. Sasaran kegiatan ini ditujukan pada dewasa muda yang bertempat tinggal di Jakarta Barat yaitu daerah pejagalan Jakarta Barat, dengan alasan dipilih nya dewasa muda pada kegiatan ini karena pada masa pandemi aktivitas fisik mereka sebagian besar di rumah, mereka jarang berolahraga serta tingkat aktivitasnya Sebagian besar dilakukan dalam rumah dan jarang olahraga.

\section{METODE PELAKSANAAN PKM}

Metode yang digunakan untuk menyelesaikan masalah adalah penyuluhan materi olahraga dan flyer. Materi yang diberikan yaitu tentang aktivitas fisik yang dianjurkan, olahraga yang benar, baik dan terukur. Tim pelaksanaan pengabdian menjelaskan terkait aktivitas fisik, olahraga, manfaat olahraga, dilanjutkan dengan olahraga yang dianjurkan, jenis aktivitas fisik yang baik dilakukan, dan tips olahraga yang aman dan baik yang dapat dilakukan dalam masa pandemi. Susunan acara kegiatan adalah : Kegiatan 13.00 - 13.20 : Pembukaan dan Pretes $13.20-$ 13.50 : Penyampaian materi mengenai aktivitas fisik dan kiat kiat olahraga yang baik selama pandemi: Sesi tanya jawab dan pos test

\section{HASIL DAN PEMBAHASAN}

Kegiatan penyuluhan edukasi kesehatan olahraga dilakukan pada tanggal 27 Mei pukul 13.00 WIB, dihadiri 15 peserta, peserta diminta mengisi daftar hadir serta pretes. Penyampaian materi disampaikan oleh dr Susy Olivia Lontoh, M.Biomed dan dibantu Yemima Graciella. Topik yang 


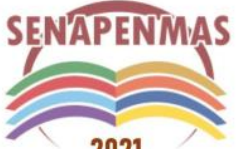

2021
Seminar Nasional Hasil Penelitian dan Pengabdian Kepada Masyarakat 2021

Pengembangan Ekonomi Bangsa Melalui Inovasi Digital Hasil Penelitian dan Pengabdian Kepada Masyarakat Jakarta, 21 Oktober 2021

disampaikan terkait aktivitas fisik, manfaatnya, tips olahraga yang baik saat pandemi, bentuk aktivitas fisik yang dapat dilakukan dirumah serta prokes kesehatan selama pandemi berdasarkan GERMAS. Sebelum kegiatan berakhir maka dilakukan tanya jawab serta pengisian pos tes. Pada sesi tanya jawab, peserta bertanya terkait materi, terkait gerakan olahraga yang dapat dilakukan dirumah, penyampaian pertanyaan oleh peserta dilakukan secara langsung maupun melalui ruang chat.

Tabel 1. Data Hasil Kegiatan Penyuluhan

\begin{tabular}{|c|c|}
\hline Variabel & $\mathbf{N}$ \\
\hline \multicolumn{2}{|l|}{ Umur (Tahun) } \\
\hline $20-30$ & 5 \\
\hline $31-40$ & 8 \\
\hline $41-50$ & 1 \\
\hline $51-60$ & 1 \\
\hline \multicolumn{2}{|l|}{ Jenis Kelamin } \\
\hline Laki-Laki & 6 \\
\hline Perempuan & 9 \\
\hline \multicolumn{2}{|l|}{ Pendidikan } \\
\hline SMA & 2 \\
\hline S1 & 13 \\
\hline \multicolumn{2}{|l|}{ Pekerjaan } \\
\hline Mahasiswa & 2 \\
\hline Ibu Rumah Tangga & 2 \\
\hline Karyawan & 11 \\
\hline \multicolumn{2}{|l|}{ Aktivitas fisik } \\
\hline Kurang & 11 \\
\hline Cukup & 4 \\
\hline \multicolumn{2}{|l|}{ Frekuensi olahraga } \\
\hline $0-1 \mathrm{x} /$ perminggu & 9 \\
\hline 2-3x/perminggu & 2 \\
\hline 3-4x/perminggu & 1 \\
\hline 4-5x/perminggu & 1 \\
\hline 5-6x/perminggu & 1 \\
\hline Lebih 6x/perminggu & 1 \\
\hline
\end{tabular}

Berdasarakan data karekteristik peserta didapatkan hasil 11 peserta aktivitas fisik kurang dan 4 peserta aktivitas cukup. 9 peserta melakukan olahraga 0-1 kali perminggu, dan kondisi ini menunjukkan masih kurangnya kesadaran untuk berolahraga serta tingginya tingkat aktivitas fisik kurang. Peningkatan pengetahuan terkait materi aktivitas fisik dari peserta dilihat berdasarkan nilai pretes dan postes. Hasil pretes yang telah diberikan kepada peserta didapatkan bahwa nilai rata-rata sebesar 67 , hasil postest didapatkan nilai rata-rata sebesar 88 , terjadi peningkatan pengetahuan sebesar $31.3 \%$. Hasil ini memperlihatkan setelah penyuluhan 
terkait aktivitas fisik maka terjadi peningkatan wawasan aktivitas fisik yang cukup baik.

Pada edukasi kesehatan materi penyuluhan olahraga disampaikan bentuk olahraga aerobik yang dapat dilakukan di rumah adalah jalan kaki 1000 langkah perhari, jalan cepat sekeliling rumah, naik turun tangga di dalam rumah selama 10-15 menit dan dapat dilakukan 2-3 kali sehari, senam aerobik selama 30-60 menit seminggu 3-5X, menari santai 10-30 menit. Jika tidak sempat berolahraga maka kami menyampaikan untuk aktivitas fisik di dalam rumah seperti membersihkan rumah, berkebun, atau olahraga memanfaatkan perabotan rumah, kursi, sofa sehingga melatih kekuatan otot, seperti gerakan push up, yaitu push up sambil berdiri dengan dinding sebagai landasan untuk menggantikan lantai.

Tips olahraga juga kami uraikan seperti olahraga sesuai kemampuan, menggunakan perlengkapan olahraga yang benar, 2 jam sebelum berolahraga jangan makan kenyang, sesudah olahraga minum yang cukup, jangan lupa melakukan pemanasan -pendinginan serta menerepkan protokol kesehatan selama pandemi Covid-19 seperti sebelum dan sesudah olahraga mencuci tangan dengan sabun dan air mengalir, menghindari kerumunan orang, menjaga jarak dengan orang sekitar, tidak berpelukan atau berjabat tangan, selama berolahraga membawa peralatan olahraga sendiri, setelah berolahraga mengganti pakaian serta jika kondisi suhu tubuh sudah stabil dianjurkan mandi.

Manfaat yang didapatkan melakukan olahraga teratur meningkatkan kesehatan kardiovaskular seperti melatih kontraksi jantung, kekuatan paru, menjaga tekanan darah agar tidak meningkat, meningkatkan pembaran lemak sehingga obesitas dapat dicegah serta imunitas tubuh juga baik.
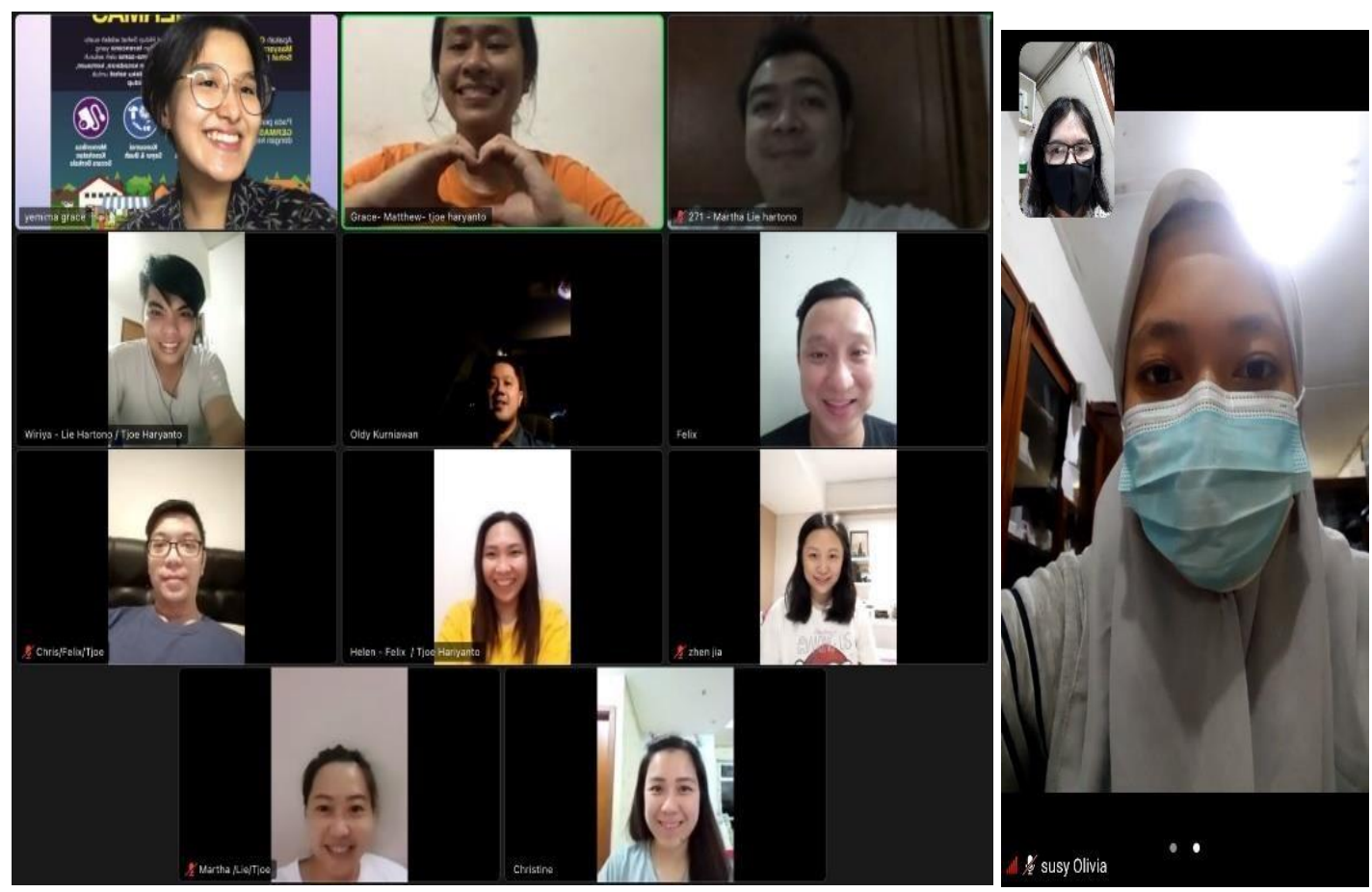

Gambar 1. Peserta kegiatan bakti kesehehatan 

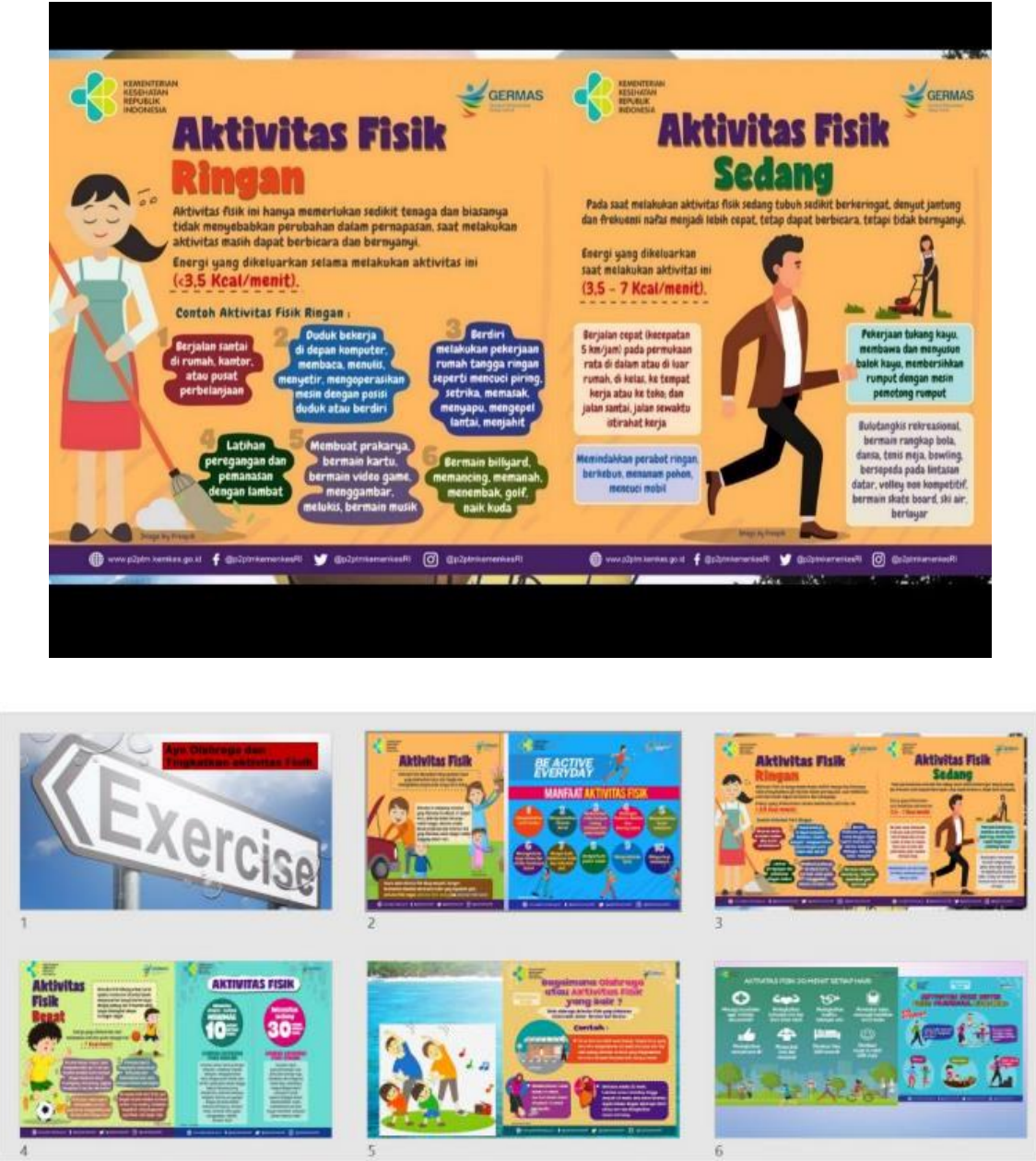

Gambar 2. Penyampaian materi oleh narasumber

\section{KESIMPULAN}

Edukasi kesehatan dalam bentuk penyuluhan aktivitas fisik dan olahraga yang merupakan program edukasi kesehatan terhadap target sasaran program pengabdian ini dapat dilaksanakan dengan baik, dapat dipahami serta dimengerti. Hasil posttest memperlihatkan setelah penyuluhan terjadi peningkatan pengetahuan terkait aktivitas fisik dan olahraga. Penyuluhankesehatan terkait olahraga dan aktivitas fisik dapat berdampak ke peserta sehingga memperbaiki pola hidup, rutin berolahraga serta dapat mengajak anggota keluarga untuk berolahraga dan tetap aktif.

\section{Ucapan Terima Kasih}

Terima kasih kami haturkan kepada Lembaga Penelitian dan Pengabdian kepada Masyarakat Universitas Tarumanagara atas pendanaan dalam kegiatan ini. Terima kasih kepada seluruh peserta yang berpartisipasi dalam kegiatan bakti kesehatan, sehingga kegiatan dapat dilakukan sesuai rencana. Terima kasih juga disampaikan kepada Tim PKM 100 UNTAR atas kesempatan dan dukungannya dalam pelaksanaan kegiatan bakti kesehatan ini.

\section{REFERENSI}

Booth FW, Roberts CK, Thyfault JP, et al. Role of inactivity in chronic diseases: evolutionary insight and pathophysiological mechanisms. Physiol Rev.2017;97(4): 13511402.https://doi.org/10.1152/physrev.00019.2016 


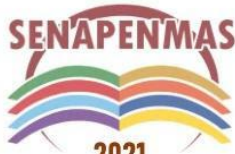

2021

CDC Newsroom [Internet]. Centers for Disease Control and Prevention; 2020 [cited 2020 Dec 14]. Available from: https://www.cdc. gov/media/releases/2020/s0917-adultobesityincreasing.html

Dominski FH, Brandt R. Do the benefits of exercise in indoor and outdoor environments during the COVID-19 pandemic outweigh the risks of infection? Sport Sci Health. 2020 Jul 17:16. doi: 10.1007/s11332-020- 00673-z. Epub ahead of print. Erratum in: Sport Sci Health. 2020 Aug 17;:1. PMID: 32837566; PMCID: PMC7366884.

Kemenkes. 2020. Aktivitas Fisik di Masa Pandemi COVID-19 Bagi Orang dengan Faktor Risiko PTM. http://www.p2ptm.kemkes.go.id/kegiatan-p2ptm/dki-jakarta/aktivitas-fisik-di-masapandemi-covid-19-bagi-orang-dengan-faktor-risiko-ptm-2

Kemnkes.2020. Aktivitas Fisik Dan Olahraga Di Rumah Yang Rutin Dengan Cara Yang Tepat Dapat Meningkatkatkan Daya Tahan/Imunitas.

http://www.p2ptm.kemkes.go.id/infographic- p2ptm/obesitas/page/4/aktivitas-fisik-danolahraga-di-rumah-yang-rutin-dengan-cara-yang-tepat-dapat- meningkatkatkan-dayatahan-imunitas

Pedersen BK, Saltin B. Exercise as medicine - evidence for prescribing exercise as therapy in 26 different chronic diseases. Scand J Med Sci Sports. 2015;25(Suppl 3): 1-72. https://doi.org/10.1111/sms.12581

WHO. Coronavirus disease (COVID-19): Staying active.2020. https://www.who.int/emergencies/diseases/novel-coronavirus-2019/question-and-answershub/q-a- detail/coronavirus-disease-covid-19-staying-active

WHO. The top 10 causes of death, 9 December 2020 [Internet]. World Health Organization; 2020 [cited 2020 Dec 14]. Available from: https://www. who.int/news-room/factsheets/detail/the-top-10- causes-of-death

WHO. Coronavirus Disease (COVID-19) Dashboard, 14 Desember 2020 [Internet]. World HealthOrganization; 2020 [cited 2020 Dec 14]. Available from: https://covid19.who.int/ 3. CDC. New CDC datafinds adult obesity is increasing.

WHO.2020. Physical Activity. https://www.who.int/news-room/fact-sheets/detail/physicalactivity

Pascoe M, Bailey AP, Craike M, et al. Physical activity and exercise in youth mental health promotion: a scoping review. BMJ Open Sport Exerc Med. 2020;6(1), e000677. https://doi.org/10.1136/bmjsem-2019- 000677

Zachary Z, Brianna F, Brianna L, et al. Selfquarantine and weight gain related risk factors during the COVID- 19 pandemic. Obes Res Clin Pract. 2020 May-Jun;14(3):210-216. doi: 10.1016/j.orcp.2020.05.004 